\title{
El uso de la documentación con una nueva formación política: Podemos
}

\author{
Rubén Rivas DE RocA GARCÍA \\ Universidad de Sevilla \\ rubrivgar@alum.us.es
}

Recibido: 30 de septiembre de 2015

Aceptado: 4 de abril de 2016

\begin{abstract}
Resumen
Esta investigación pretende analizar, desde un punto de vista documental, el tratamiento periodístico dado por los principales medios impresos españoles a las informaciones sobre el nuevo partido político Podemos en el momento de su eclosión. Podemos es un fenómeno social que en muy breve espacio de tiempo cambió los parámetros políticos de España. Por ello, queremos conocer cómo los principales medios de comunicación elaboraron sus informaciones en ese contexto de novedad que supuso su aparición. La documentación es el pilar de la información periodística de calidad, razón por la que nos servimos de ella para medir, dentro del marco de nuestra investigación, la calidad del periodismo que se practicó con dicha formación política.
\end{abstract}

Palabras clave: Podemos, Fuentes de información, Documentación Periodística, Periodismo político.

\section{The use of documentation with a new political formation: Podemos}

\begin{abstract}
This research aims to analyze, from a documentary point of view, the journalistic treatment given by the main Spanish printed media to the information about the new political party Podemos at the time of hatching. Podemos is a social phenomenon that in a very short period of time has changed the political parameters in Spain. Therefore, we want to know how the mainstream media managed the information in the context of innovation that its appearance brought. Information Science is the ground of high-quality journalistic information, thus we use it to measure, within the frame of our research, the quality of the journalism that was practiced with this political party.
\end{abstract}

Keywords: Podemos, Information sources, Journalistic Information Science, Political journalism.

\section{Referencia normalizada}

RIVAS DE ROCA GARCÍA, Rubén (2016): "El uso de la documentación con una nueva formación política: Podemos". Estudios sobre el Mensaje Periodístico. Vol. 22, Núm. 1 (enero-junio), págs.: 503-516. Madrid, Ediciones Complutense.

Sumario: 1. Introducción. 2. Metodología de la investigación. 3. La documentación como parámetro de calidad periodística. 4. Resultados y discusión; 4.1. Datos generales; 4.2. Fuentes de información; 4.3. Número de fuentes; 4.4. Identificación de las fuentes; 4.5. Oficialidad de las fuentes; 4.6. Tipos de fuentes. 5. Conclusiones. 6. Referencias bibliográficas.

\section{Introducción}

El presente proyecto de investigación pretende realizar un estudio sobre la utilización de las fuentes de información que los medios de comunicación escritos realizaron con el partido político Podemos en el momento de su aparición en la escena pública. En esta investigación tratamos de conocer este uso tomando como punto de partida la publicación del barómetro n³041 del CIS (Centro de Investigaciones Sociológicas), referente a octubre de 2014. Esta encuesta informaba de que Podemos recibiría un 22,5\% de los votos en unas hipotéticas elecciones, aupándose así como tercera opción política, y tan solo a 5 puntos porcentuales de la primera. 
Lo relevante del barómetro del CIS de octubre de 2014 es que situaba por primera vez desde 1980 a una formación política distinta a PSOE y PP (hasta 1989 denominada Alianza Popular) como posibilidad real de gobierno en España. Por ello, resulta de interés valorar el tratamiento mediático que desde la prensa se proporcionó a este nuevo grupo político. Queremos conocer si la información que se ha proporcionado sobre Podemos ha seguido los criterios de calidad periodística de acuerdo a una utilización correcta y plural de las fuentes de información. Las fuentes suelen ser consideradas como la base de toda información periodística y, por ende, las que determinan en buena medida su grado de calidad. Para José Javier Muñoz las fuentes de información son "el origen de la noticia propiamente dicho y las personas físicas y jurídicas que facilitan los datos" (Pérez Curiel, 2005: 171). Esto nos impulsa a centrar en las fuentes un estudio mediático sobre Podemos a través del análisis de la prensa escrita.

Aunque este tipo de prensa atraviesa una fuerte crisis en nuestro país, traducida según el Libro Blanco de la Prensa Diario 2014 en una pérdida de un millón de lectores en la última década (2004-2014) y en que España ocupa el penúltimo lugar en el ranking de la Unión Europa sobre lectura de rotativos, consideramos que la prensa sigue siendo la base del sistema informativo español. Son los periódicos los que han destapado los últimos grandes casos de corrupción de este país (trama Gürtel, caso EREs, etc.), dedicándose los otros medios de comunicación social a reproducir lo descubierto inicialmente por los de naturaleza escrita. La prensa es por tanto creadora de tendencia, de lo que se deduce que el tratamiento mediático que aplique a Podemos puede ser el que luego desarrollen el resto de medios.

Esta investigación pretende, por tanto, a partir de un análisis científico desde un punto de vista documental de las informaciones publicadas sobre Podemos en la prensa, extraer conclusiones sobre la calidad documental del periodismo a la hora de cubrir informaciones que atañen a este partido político, dentro de los parámetros de nuestra investigación. Para ello se realizará como trabajo de campo un análisis de la prensa, recogiendo datos que se valorarán después a partir de una fundamentación teórica.

Sin embargo, dado que es una investigación cuantitativa de la que posteriormente sí se obtendrán interpretaciones más cualitativas, este estudio presenta una serie de objetivos adyacentes:

- Valorar la calidad del periodismo político basado en recursos documentales aplicado a Podemos a través de los siguientes indicadores de calidad: número de informaciones y sus posibles efectos desinformativos, y fuentes (número de ellas, identificación o no de las mismas, oficialidad o no de las mismas y tipología de fuentes consultadas).

- Averiguar qué tipo de fuentes son las más recurrentes en las informaciones sobre este grupo político.

\section{Metodología de la investigación}

El objeto de estudio es la prensa escrita y su cobertura del partido Podemos a raíz del barómetro del CIS (5 de noviembre de 2014). Para delimitar de forma abarcable y a la vez científica, se ha establecido un período de análisis de un mes, del 6 de noviembre al 6 de diciembre de 2014, es decir, el mes siguiente a la publicación de la en- 
cuesta, tiempo que consideramos suficiente para medir las reacciones mediáticas a este hecho. Se ha establecido como fecha de inicio de la investigación el día 6 porque fue la jornada inmediatamente posterior a que se hiciera público el barómetro, y es por tanto el primer día en el que los medios escritos pudieron dar cuenta de la importante posición de Podemos ante unas elecciones. En cuanto a los periódicos a analizar, se ha decidido estudiar los cuatro generalistas más leídos a nivel nacional de acuerdo al EGM (Estudio General de Medios) más reciente del momento, que recogía datos de octubre de 2013 a mayo de 2014. Según el EGM, los cuatro diarios generalistas más leídos en España eran: El País (1.685.000 lectores), El Mundo (1.032.000), La Vanguardia (690.000) y La Voz de Galicia (594.000). Todos estos datos refieren al número de lectores en cuanto a difusión de las ediciones impresas.

Antes del análisis hay una fase de selección de las noticias. Del total de informaciones publicadas en el período temporal escogido por El País, El Mundo, La Vanguardia y $L a$ Voz de Galicia, se seleccionarán aquellas que utilicen géneros informativos y que tengan como tema principal a la formación política Podemos o a sus dirigentes. La elección única de géneros informativos se encuentra motivada porque son las piezas de este género las que más se fundamentan en fuentes. En los textos opinativos la documentación no tiene por qué darse y, aunque exista, no posee la obligación de justificarse en parámetros de rigor periodístico. Por su parte, con tema principal nos referimos a que Podemos ha de ser la piedra angular en torno a la que gire la noticia. Ejemplificando la metodología, será objeto de estudio la noticia que cuente el ascenso en intención de voto de Podemos, pero no la que presente esta subida como un dato más dentro del cambio en el panorama político español. En el caso de noticias sobre personalidades de esta formación (dirigentes), solo se tendrán en cuenta aquellas que refieran a estos personajes por asuntos vinculados a la política.

Tras seleccionar las informaciones según los criterios anteriores y durante el período indicado, las someteremos a un análisis a través de una ficha analítica. En ella, se han desarrollado distintas categorías que contribuyen a un mejor análisis cuantitativo de los resultados, entendidos como criterios de calidad periodística. A continuación detallamos los campos y las razones por la que estos apartados son criterios de calidad y, por tanto, objetos de estudio para nuestra investigación: número de fuentes, identificación de las fuentes, carácter de las fuentes y tipos de fuentes.

Número de fuentes. La cantidad de fuentes de una información suele ser valorada como criterio de calidad periodística. Tradicionalmente, el contraste de fuentes ordenado por la deontología periodística exige un mínimo de dos, situando en un número ideal de tres la cifra de fuentes con la que debería contar una información (Casero Ripollés y López Rabadán, 2013: 79). Para esta investigación hemos establecido cinco categorías en este campo: 0 fuentes, $1,2,3$, y 4 o más. Los casos de 0 y 1 fuente serían deficientes periodísticamente, si bien es también cierto que un mayor número de fuentes no siempre provoca necesariamente más calidad periodística (por ejemplo, pueden ser todas de la misma orientación), aunque a priori asegura niveles más altos de pluralidad.

Identificación de las fuentes. Con identificación nos referimos al modo en que las fuentes son referenciadas. Se pueden establecer dos grandes tipos de atribu- 
ciones con las fuentes en la prensa escrita, divisibles a su vez en otras modalidades (Borrat 1989: 57-58). Borrat diferencia entre atribución directa, en la que se identifica claramente a la fuente y la información que esta ha proporcionado, y con reservas, en la que la fuente aparece identificada de forma difusa. A partir de estas tipologías, y en aras de evitar confusiones, hemos establecido en nuestra ficha de análisis tres categorías: Atribución directa, Sin identificar y Ambas. En Atribución directa se enmarcaran todas las informaciones que identifiquen de forma clara a la fuente, es decir, con nombre y apellidos a las fuentes personales, y con nombre y procedencia a las de tipo documental, mientras que en Sin identificar se anotarán todas aquellas informaciones que presenten a las fuentes de manera inconcreta, o bien que simplemente no las identifiquen. Por su parte, el ítem Ambas incluye aquellas noticias en las que coincidan los dos tipos comentados de identificación.

- Carácter de las fuentes. Sobre las fuentes de información, existe "una extensa tipología establecida en orden a criterios como el soporte (escritas y orales), la cercanía a los hechos (primarias y secundarias), el número de personas que las conforman (individuales y colectivas)" (Pérez Curiel, 2005: 85). Dentro de las múltiples clasificaciones que recoge esta autora, hemos optado por desarrollar la referida al carácter de las fuentes, esto es, a su grado de oficialidad, y que distingue entre fuentes oficiales y no oficiales. Para cubrir todas las noticias, hemos creado en esta investigación tres categorías a partir de dicha clasificación: Oficiales, No oficiales y Ambas. Con Oficiales nos referimos a noticias basadas únicamente en la visión de instituciones, ya sean públicas o privadas; las no oficiales cubren las informaciones que no plasman la visión de una institución, sino de otra fuente, mientras que Ambas combina el uso de las dos anteriores.

Tipología de fuentes. Además de su carácter, hemos decidido analizar de forma diferenciada las modalidades de las fuentes. Las fuentes suelen clasificarse en dos tipos según su origen: personales y documentales (Pérez Curiel, 2005: 85). Basándonos en esta división, hemos establecido dos grandes variables para clasificar los tipos de fuentes: Personales y Documentales. Con Personales nos referimos a información proporcionada por sujetos físicos, Por su parte, Documentales engloba aquellos datos que proceden de documentos en cualquier soporte físico (papel, audiovisual, electrónico, sonoro, etc.).

Como se puede observar, hemos creado cuatro ítems sobre las fuentes de información: Número de fuentes, Identificación de las fuentes, Carácter de las fuentes y Tipos de fuentes. La razón de que las fuentes ocupen una posición predominante en nuestra ficha de análisis radica en que constituyen la base de la noticia, y deben de ser la garantía de la verificación, algo que vendrá determinado por la cantidad, la calidad (credibilidad) y la pluralidad de fuentes (Casero Ripollés y López Rabadán, 2013: 79), aspectos que hemos tratado de tener en cuenta en nuestra investigación sobre el tratamiento documental del partido Podemos.

\section{La documentación como parámetro de calidad periodística}

Para utilizar de forma adecuada la información nos proporcionan las fuentes políticas hace falta contextualizar, documentarse. La disciplina que se encarga de ello es la Do- 
cumentación Periodística, que aparece por el crecimiento del volumen informativo, un crecimiento que lleva a la especialización de contenidos" (García Gutiérrez, 1999: 450). Por ello, solo a través de la investigación y el buen uso de la documentación el periodista va a poder producir información que cubra las necesidades de los lectores. "Saber autodocumentarse supone, en pocas palabras, saber buscar y recuperar las fuentes documentales que se necesitan para cubrir tales necesidades informativas" (López Hernández, 2000: 131). Gracias a la documentación, el periodista puede tener además una amplia perspectiva del tema del que habla, con lo que consigue controlar la información y evitar asimismo que esta le sobrepase.

La Documentación Periodística, y las fuentes que en ella se emplean, pueden ser utilizadas como medidores de la calidad de las informaciones. Los recursos documentales o fuentes de información son un elemento clave del periodismo, tanto que se llega a afirmar que sin ellas no hay periodismo (Casero Ripollés y López Rabadán, 2013: 73). Las fuentes desarrollan un papel fundamental en la producción de información y en la selección de lo que es noticia, llegando por tanto a condicionar el producto final. Todo ello hace que la búsqueda de fuentes y las relaciones que estas poseen con los periodistas adquieran importancia. Sin embargo, las fuentes no son simples abastecedores de la información, sino que además, "con mucha (y creciente) frecuencia, esperan obtener un beneficio de su acercamiento a los periodista" (Mayoral, 2005: 94). A este respecto, se afirma que "los medios de comunicación no son solo emisores, sino muy primariamente son receptores de los mensajes que emiten sus fuentes" (Pérez Curiel, 2005: 85). Las fuentes tratan por tanto de imponernos también unos puntos de vista.

Debido a su rol como piedra angular de las informaciones, las fuentes están relacionadas directamente con la calidad periodística, un intangible del que depende la credibilidad de los medios y, por ende, su propia existencia. De esta manera expresan la importancia de las fuentes Casero Ripollés y López Rabadán:

"Su gestión puede impulsar u obstaculizar la elaboración de productos periodísticos basados en la excelencia. Por lo tanto, el empleo de unas u otras fuentes actúa como un control de calidad de la actividad profesional desarrollada por los periodistas" (Casero Ripollés y López Rabadán, 2013: 74).

Estos autores establecen un conjunto de criterios de calidad vinculados a las fuentes, a partir de la diferenciación entre dos niveles: interno y externo. El nivel interno alude a aspectos que tienen que ver con el proceso de producción de la información periodística, mientras que el externo refiere a la propia gestión de las fuentes (Casero Ripollés y López Rabadán, 2013: 75-76). Al ser el nivel externo el apreciable en una investigación como la nuestra, hemos decidido tomar como base esos indicadores, que son cuatro: credibilidad ("la cantidad y la diversidad de fuentes otorgan credibilidad a la noticia"), influencia (que tiene que ver con la credibilidad, de modo que cuanto mayor sea la credibilidad más alto es el nivel de influencia de la información), pluralismo (que se encuentra unido al número de fuentes citadas y a su variedad en la procedencia), y participación (es decir, la inclusión de la sociedad como fuente fun- 
ciona como criterio de calidad periodística) (Casero Ripollés y López Rabadán, 2013: 76-78).

Los criterios referidos pueden ser medidos a través de un análisis sistemático de los medios de comunicación. Según su propuesta, el estudio tendría tres variables: número total de fuentes, tipo de identificación y tipología de las fuentes (oficiales o no, personales o documentales, etc.). Cada una de estas variables presenta una serie de indicadores de calidad asociados. La variable número total de fuentes nos permite conocer los niveles de verificación, relevancia, credibilidad e influencia, la variable tipo de identificación informa de la transparencia, credibilidad e influencia y la variable tipología de las fuentes refiere al pluralismo, participación e influencia (Casero Ripo1lés y López Rabadán, 2013: 79).

Para esta investigación, que trata de evaluar la calidad periodística de un conjunto de informaciones mediante la documentación por parte de los periodistas que las elaboran, estas aproximaciones teóricas al empleo de las fuentes suponen un referente. La matriz teórica de este estudio reside en la asunción de que una información debe poseer elementos que inciten a la confiabilidad del lector, entre los que destacan elementos propios de la documentación como las fuentes de información.

\section{Resultados y discusión}

Tras aplicar la ficha de análisis a las informaciones seleccionadas en nuestra investigación de acuerdo con los criterios ya explicados, hemos agrupado los resultados obtenidos en dos grandes bloques: Datos Generales y Fuentes de Información. Con ello, buscamos facilitar la comprensión de los resultados, al presentarlos en dos grupos que aglutinan los diferentes parámetros de la ficha de análisis.

\subsection{Datos generales}

Se han localizado 149 informaciones sobre Podemos en los diarios y período establecidos, que han sido analizadas siguiendo la ficha expuesta anteriormente. De estas informaciones, un 30\% (45 en total) han sido publicadas en el diario El País, un 20\% (29 informaciones) en El Mundo, el 13\% en el periódico regionalista catalán La Vanguardia (20 informaciones), y un 37\% en el también regionalista, en este caso gallego, La Voz de Galicia (55 informaciones).

Estos datos muestran que la cobertura informativa sobre Podemos en el período estudiado ha sido mayor en diarios situados habitualmente en el centro-izquierda ( $E l$ País y La Voz de Galicia), con un $67 \%$ del total de informaciones publicadas frente a periódicos más en el espectro liberal y de centro-derecha (El Mundo y La Vanguardia), que tienen un 33\%. Se aprecia así una mayor preocupación por recoger las noticias del nuevo fenómeno Podemos en los diarios a priori más progresistas. El periódico con más informaciones sobre esta formación política es La Voz de Galicia (55, un 37\% del total de los cuatros medios analizados). El período investigado refleja que este diario realiza un extensa cobertura de las agrupaciones locales de Podemos, lo que aumenta significativamente el número de informaciones. De sus noticias, 30 versan sobre Podemos a nivel local. Así pues, la amplia cobertura de La Voz de Galicia a escala regional aúpa a este periódico al primer puesto en el número de informaciones. En 
cambio, sus datos son muy distintos de los del otro periódico regional analizado, $\mathrm{La}$ Vanguardia que, con 20 informaciones (13\% del total), es el diario que ha prestado una menor atención a Podemos tras la publicación del CIS de octubre de 2014. La diferencia con La Voz de Galicia radica en que el periódico catalán no ha recogido ni una sola noticia del partido Podemos en el ámbito local, ciñéndose exclusivamente a temas nacionales de esta formación, como hacen El País y El Mundo, algo sorprendente cuando La Vanguardia es un periódico editado en Barcelona que dispone diariamente de una amplia sección dedicada a Cataluña.

La extensa cobertura de El País y La Voz de Galicia, con más de una información por día sobre Podemos (1,5 noticias de media a la jornada en El País y 1,83 en La Voz de Galicia), denota una cierta sobreabundancia informativa. Durante el período de un mes, un partido político que no tenía representación parlamentaria ha acaparado en estos dos periódicos más de una noticia al día. Es cierto que en ese tiempo se publicó la encuesta del CIS que asentó a Podemos como opción de Gobierno, pero durante ese mes no hubo actualidad informativa, como pudieran ser una elecciones, que justificara tal número de informaciones. Esta cifra invita a la reflexión: “¿Realmente es tan importante que el periódico se sature con todo un mosaico de informaciones escuetas en detrimento de un periodismo mejor investigado, mejor tratado en esencia?" (López Hernández y Domínguez Delgado, 2012: 801).

Teniendo en cuenta todos los diarios analizados, los datos obtenidos en este estudio corroboran una investigación de María José Canel, en la que concluyó que la información política ocupa alrededor del $80 \%$ del contenido de un diario español. De esta información, la mayor parte corresponde a la sección nacional, dedicándose más del 30\% de esta a asuntos relacionados con los partidos políticos (Blanco, 2003: 227. El elevado número de informaciones localizadas acerca de Podemos atestigua, dentro de los parámetros de nuestra investigación, la importancia de la política y, especialmente, de los partidos políticos en la prensa de nuestro país.

\subsection{Fuentes de información}

A continuación presentamos los resultados obtenidos con respecto a los cuatro parámetros de calidad informativa que hemos definido desde el enfoque de la Documentación Periodística. Estos medidores de calidad son el número de fuentes, la identificación de las mismas, su oficialidad y su tipología.

\subsection{Número de fuentes}

En cuanto al número de fuentes, desglosado por medios, los de tirada nacional presentan un mayor uso de fuentes como se ve en la Tabla 1, con una media que bordea el mínimo exigible de dos referencias establecido por la deontología (Casero Ripollés y López Rabadán, 2013: 79). Así, El País recurre a 2,06 fuentes de promedio, mientras que El Mundo lo hace a 1,93. Por su parte, en los diarios regionales analizados se observan cifras sensiblemente peores, sobre todo en La Voz de Galicia. Como se ha comentado, este periódico es el que publica más noticias en el período estudiado, hecho que puede explicar, sin que sea justificable, una menor calidad ante tanto volumen informativo. 
Tabla 1. Total de informaciones según el número de fuentes empleadas.

Fuente: Elaboración propia

\begin{tabular}{|c|r|r|r|r|}
\hline $\begin{array}{l}\text { Número de } \\
\text { fuentes }\end{array}$ & El País & El Mundo & $\begin{array}{c}\text { La } \\
\text { Vanguardia }\end{array}$ & $\begin{array}{c}\text { La Voz de } \\
\text { Galicia }\end{array}$ \\
\hline 0 & 4 & 5 & 3 & 12 \\
\hline 1 & 11 & 10 & 9 & 25 \\
\hline 2 & 16 & 4 & 4 & 8 \\
\hline 3 & 8 & 2 & 1 & 6 \\
\hline 4 o más & 6 & 8 & 3 & 4 \\
\hline $\begin{array}{l}\text { *Media de } \\
\text { fuentes por } \\
\text { noticia (5) }\end{array}$ & 2,06 & 1,93 & 1,6 & \multicolumn{1}{|c|}{1,18} \\
\hline
\end{tabular}

El parámetro Número total de fuentes nos permite conocer los niveles de verificación, relevancia, credibilidad e influencia de las informaciones. Ese número ha de estar en un mínimo de dos fuentes para asegurar la calidad de esos niveles (Casero Ripollés y López Rabadán, 2013: 79). El único que cumple ese criterio es El País. Los otros tres periódicos analizados, El Mundo, La Vanguardia y La Voz de Galicia, no demuestran que sus informaciones sean veraces, relevantes, creíbles e influyentes a través de las fuentes. Consideramos que esto es sumamente grave, ya que la veracidad y la credibilidad son la base de toda información periodística. La calidad del periodismo practicado por estos medios con Podemos durante el período estudiado se ve muy resentida ante la escasez de fuentes.

\subsection{Identificación de las fuentes}

De las 149 informaciones seleccionadas para nuestra investigación, 24 no exponían ningún tipo de fuente en el texto periodístico. Por tanto, se ha reducido a 125 el número de informaciones que son objeto de estudio para conocer su forma de identificación de las fuentes. Este parámetro es importante porque nos informa de la transparencia, credibilidad e influencia de las informaciones (Casero Ripollés y López Rabadán, 2013: 79).

El 74\% del total estudiado presenta una identificación de fuentes exclusivamente directa, es decir, el 74\% de las informaciones identifica correctamente a todas las fuentes que se han consultado. Este elevado porcentaje nos informa de una correcta atribución de las fuentes, lo que aumenta la credibilidad y la transparencia, clave para poder determinar quién nos habla. En segundo lugar se halla la variable Ambas $(15 \%)$, que contiene noticias en las que se combinan fuentes identificadas con otras que no se atribuyen. No se trata de una mala práctica solo porque impida conocer a ciencia cierta algunas fuentes, sino que, además, al identificar unas y no otras se da sensación de falta de criterio y, por ende, de escasa credibilidad. El porcentaje más reducido corresponde al método más ocultista, es decir, la categoría Sin identificar, que corresponde a informaciones que no identifican ninguna de sus fuentes. Esta fórmula, que atenta totalmente contra el principio de claridad que exige la deontología periodística, se da en el $11 \%$ de los casos analizados.

Los datos analizados muestran una tendencia positiva en cuanto a la identificación de las fuentes. Sumando las situaciones de Atribución directa y Ambas obtenemos que el $89 \%$ de las informaciones tienen, de una u otra forma, fuentes atribuidas. A 
ello se une que el $74 \%$ del conjunto de informaciones presenta a todas sus fuentes identificadas. Estas cifras evidencian que las informaciones estudiadas se caracterizan por partir de fuentes oficiales y personales, de ahí que la plena identificación sea en principio más sencilla. Sin embargo, no se puede obviar que un $26 \%$ de informaciones no presenta correctamente a las fuentes, cuando lo ideal sería que todas las fuentes se encontrasen bien identificadas.

Por medios, se mantiene una correspondencia con los datos generales, excepto en el caso de El Mundo, en el que solo el $58 \%$ de las informaciones presentan a sus fuentes de forma directa. Se observa por tanto una mala práctica de este diario en comparación con el resto de los estudiados, siendo además el periódico en el que más se produce la modalidad mixta de combinar fuentes bien identificadas con otras sin identificar (29\%). Este método tampoco puede considerarse acorde a la calidad periodística, ya que lo ideal es identificar plenamente a todas las fuentes.

Tabla 2. Porcentaje de informaciones por medios según la identificación de las fuentes (\%). Fuente: Elaboración propia

\begin{tabular}{|l|l|l|l|}
\hline \multicolumn{1}{|c|}{ Periódicos } & $\begin{array}{c}\text { Atribución } \\
\text { directa }\end{array}$ & $\begin{array}{c}\text { Sin } \\
\text { identificar }\end{array}$ & Ambas \\
\hline El País & $71 \%$ & $7 \%$ & $22 \%$ \\
\hline El Mundo & $58 \%$ & $13 \%$ & $29 \%$ \\
\hline La Vanguardia & $82 \%$ & $18 \%$ & - \\
\hline La Voz de Galicia & $81 \%$ & $12 \%$ & $7 \%$ \\
\hline
\end{tabular}

Destaca también que los medios que más atribuyen de forma directa son los regionales, La Vanguardia y La Voz de Galicia, un hecho que puede venir motivado porque son periódicos afectados por menores intereses hacia Podemos, razón de que no tengan nada que esconder. El País y El Mundo son diarios que, en cambio, tienen la capacidad de dictar la agenda política nacional, lo cual, sin embargo, no debería ser excusa para atribuir de forma directa a las fuentes. Eso sí, los porcentajes observables en la Tabla 2 son positivos y denotan que la identificación de las fuentes informativas se han hecho en la mayoría de los casos con cierta calidad.

\subsection{Oficialidad de las fuentes}

Con respecto al grado de oficialidad de las fuentes, un parámetro que nos muestra hasta qué punto los mensajes de las instituciones se cuelan en el periodismo, el $45 \%$ de las informaciones estudiadas presenta únicamente fuentes oficiales. Sin embargo, no supone una gran distancia con las modalidades Ambas y No oficiales. Ambas se produce en el 34\% de las noticias; esto quiere decir que en esas informaciones se combinan tanto fuentes oficiales como no oficiales, lo que constituye el paradigma ideal periodístico de dar espacio a voces de distinta naturaleza. Por su parte, el $21 \%$ de las informaciones presenta un uso exclusivo de fuentes no oficiales. Se tratan pues de noticias que recurren exclusivamente a fuentes de carácter privado, nunca representantes de instituciones.

Los resultados obtenidos sitúan en primera posición el uso exclusivo de fuentes oficiales. No es una práctica positiva, en cuanto esta utilización supone conceder un es- 
tatus de superioridad a unas fuentes por su carácter oficial, oficialidad que hace que defiendan unos intereses muy particulares, los de su empresa o institución. En el caso del periodismo político, la prensa termina por convertirse en portavoz de los mensajes de los políticos, que además suelen venir cargados de eufemismos que nos impiden la comprensión del hecho (Herrero Aguado y García Gordillo (2003: 252).

Aunque el empleo de fuentes oficiales es el más numeroso (45\%), no es una cifra demasiado alta, ya que la suma de las otras dos variables estudiadas (Ambas y No oficiales) los supera con el 55\%. Así pues, el 55\% de las informaciones refleja de alguna manera impresiones de fuentes no oficiales, es decir, la mayoría de las noticias publicadas tienen en cuenta estas voces alternativas. Esto no exime de que el porcentaje de únicamente fuentes oficiales es alto, y de que la fórmula de la combinación de fuentes no se encuentra en la primera posición (34\%, que la convierte en la segunda en este ranking), algo reivindicable en aras de una pluralidad de voces desde el punto de vista del grado de oficialidad.

Por periódicos, la mayor combinación de fuentes oficiales y no oficiales (método considerado ideal por la deontología periodística) se produce en los medios nacionales, con cifras casi calcadas en El País y El Mundo, como se aprecia en la Tabla 3. Este último diario es el único en que el empleo mixto de fuentes oficiales y no oficiales es superior al uso exclusivo de oficiales. En todos los periódicos estudiados se aprecia sin embargo un excesivo peso de las fuentes oficiales, que alcanza cotas muy elevadas en La Vanguardia. Los datos por medios corroboran la enorme trascendencia de la oficialidad apuntada por los resultados generales, a la vez que señalan a los diarios regionales como los que menos complementan las informaciones.

Tabla 3. porcentaje de grado de oficialidad de las fuentes por medios (\%).

Fuente: Elaboración propia

\begin{tabular}{|l|l|l|l|}
\hline Periódicos & Oficiales & No oficiales & Ambas \\
\hline El País & $41 \%$ & $18 \%$ & $41 \%$ \\
\hline El Mundo & $33 \%$ & $25 \%$ & $42 \%$ \\
\hline La Vanguardia & $70 \%$ & $6 \%$ & $24 \%$ \\
\hline La Voz de Galicia & $46 \%$ & $28 \%$ & $26 \%$ \\
\hline
\end{tabular}

La utilización de fuentes oficiales con el partido Podemos en nuestra investigación es menor que la observada otros estudios sobre el resto de formaciones políticas (Casero Ripollés y López Rabadán, 2013: 79), en los que se expone que un 51,6\% de las fuentes son oficiales y gubernamentales. Sin embargo, los resultados de nuestra investigación sitúan al ítem Oficiales como el más cuantioso (45\%), lo que impide también aquí que se pueda hablar de un periodismo especializado, sino más bien de uno de declaraciones y pasivo. Por ello, se debe exigir una mejora en este apartado de oficialidad de las fuentes que, aunque no acumula unos datos nefastos, tiene margen para, con respecto a Podemos, ser menos portavoz de las instituciones y empresas y otorgar más voz a la ciudadanía. Se lograría así conseguir un periodismo social, que ayude a una construcción inclusiva de la sociedad a través de "una visión más abarcativa con la incorporación de nuevas fuentes" (Cytrynblum, 2009: 73). 


\subsection{Tipos de fuentes}

En las 125 informaciones con fuentes analizadas se han localizado 246 referencias. De ellas, 162 son personales, representando el $66 \%$ del total. Por su parte, se han encontrado 82 referencias documentales, lo que porcentualmente supone un $34 \%$.

Estas cifras evidencian cómo el uso de fuentes personales es mayoritario, algo habitual en el periodismo de nuestros días, si bien la cifra de fuentes documentales no es residual. Hay que tener en cuenta que el valor de las fuentes documentales radica en que añaden un mayor poso de investigación y de base científica frente a las personales. Es cierto que los documentos también son manipulables, pero como elemento físico gozan de un soporte material acreditable frente a las meras palabras. En este caso, los resultados totales reflejan que las declaraciones (fuentes personales) han sido la base más utilizada para construir informaciones.

La tipología de las fuentes sirve como criterio de calidad periodística porque mide los niveles de pluralismo, participación e influencia de las informaciones (Casero Ripollés y López Rabadán, 2013: 79). En nuestro caso, la mayoría de las informaciones proceden de fuentes personales, en su mayoría portavoces oficiales u oficiosos de instituciones. El problema es que un predominio de estas fuentes suele suponer un periodismo de mala calidad, ya que, por su parcialidad, menguan la credibilidad, despreocupándose los periodistas así de la necesaria verificación de la información (Díaz Nosty, 2011: 22). Frente a esto, los recursos documentales constituyen una garantía en pro del rigor. Lamentablemente, los datos totales obtenidos en nuestra investigación concuerdan con las prácticas de exceso de fuentes personales propias del periodismo político español: "los políticos profesionales son fuentes básicas de la información política" (Herrero Aguado y García Gordillo, 2003: 246). Con respecto a las informaciones sobre Podemos, se debe exigir una mejora en la combinación de fuentes personales y documentales, por parte de los periodistas. Que dos de cada tres fuentes sean orales (personales) desvirtúa la calidad del periodismo, a la vez que reduce su credibilidad.

En cuanto a la tipología de las fuentes por medios, observamos también cómo hay claramente unos periódicos que conceden una mayor importancia a unas fuentes que a otras. El País y La Vanguardia presentan unos datos bastante similares. Ambos otorgan un gran peso a las fuentes personales, el $75 \%$ y el $78 \%$ de sus fuentes son de esta modalidad, mientras que las documentales poseen un espacio reducido: el $25 \%$ en $E l$ País y el 22\% en La Vanguardia. Por su parte, la situación en El Mundo y La Voz de Galicia es inversa a la de los dos diarios anteriores. Estos dos periódicos combinan en porcentajes muy similares fuentes personales y documentales. En El Mundo existe un equilibrio, ya que el $52 \%$ de las referencias son personales y el $48 \%$ documentales, mientras que los resultados de La Voz de Galicia muestran un 58\% de personales y un $42 \%$ de documentales, también datos muy parejos.

Afirmamos por tanto que los periódicos que durante el período de investigación combinan más fuentes personales y documentales son El Mundo y La Voz de Galicia. Con ello, estos dos diarios llevan a cabo una buena praxis periodística, que consiste en contrastar las fuentes personales con documentos, evitando otorgar un gran espacio a las personales debido a su tendencia a la parcialidad. Todo lo contrario de lo que 
realizan los otros dos medios estudiados (El País y La Vanguardia), para los cuales las fuentes personales (orales) fueron el fundamento de sus informaciones sobre Podemos durante el mes analizado. Este predominio de las fuentes orales provoca que el periódico dé cobertura a la estrategia comunicativa de los políticos, puesto que existe "una relación directa entre el uso de fuentes y las agendas informativas de los medios" (García Gordillo et al, 2013: 46). En El País y La Vanguardia, esa relación se observa en que la agenda sobre Podemos pasa, según los datos obtenidos, por recoger declaraciones de personalidades políticas.

\section{Conclusiones}

En los medios de comunicación y período investigados hemos llegado a la conclusión de que el partido político Podemos tuvo una amplia cobertura mediática, en general, tras la encuesta del CIS que lo confirmaba como opción de Gobierno. No obstante, el número de informaciones fue superior en los periódicos asociados tradicionalmente a la ideología de centro-izquierda (El País y La Voz de Galicia) que en los de centro-derecha (El Mundo y La Vanguardia). El volumen de noticias en los de centro-izquierda, casi dos informaciones de media al día, fue tal que consideramos que se puede hablar de saturación informativa. Este fenómeno tiene consecuencias desinformativas, en tanto que el lector desarrolla dificultades para discernir lo importante de lo anecdótico ante tal cantidad de noticias.

Con respecto al uso de la Documentación Periodística en ese período, los datos obtenidos en nuestra investigación son ciertamente preocupantes para la calidad periodística. El número de fuentes es bajo, e inferior, de media, a excepción de El País, al mínimo de dos exigido por la deontología periodística, repercutiendo en la veracidad y la credibilidad de las informaciones. La transparencia de las mismas sí es más positiva, ya que la identificación practicada con las fuentes es correcta en un 74\% de los casos. Sin embargo, su grado de oficialidad es alto. El elevado número de noticias solo con fuentes oficiales ( $45 \%$ del total) hace que prácticamente la mitad de las informaciones esté bajo la sombra de la duda por las carencias de rigor y, sobre todo, los intereses que caracterizan a estas fuentes. Por otro lado, en cuanto a la tipología de fuentes, la mayoría son personales. Las documentales solo representan un tercio del conjunto de fuentes utilizadas, lo que resta pluralismo y profundidad a la información.

Finalmente, concluimos que, durante el mes estudiado, se ha realizado un periodismo de baja calidad con Podemos de acuerdo a los parámetros de calidad periodística vinculados a la documentación. La actividad periodística ha distado mucho de ser especializada al no seguir los diarios analizados los criterios documentales de calidad periodística. Es exigible que los medios de comunicación escritos más importantes de nuestro país aumenten su número de fuentes, disminuyen el peso de la oficialidad en las mismas y utilicen un mayor volumen de recursos documentales, en aras de aumentar la confiabilidad de sus informaciones. Únicamente el nivel de identificación de las fuentes mantuvo datos aceptables durante esta investigación sobre la calidad periodística fundamentada en la documentación. Es cierto que Podemos supuso una fuerte novedad, capaz de alterar los parámetros del periodismo político establecidos hasta la fecha, pero es necesario que la prensa esté capacitada con fuente sólidas para afrontar estos cambios con garantías. 


\section{Referencias bibliográficas}

BLANCO, Elena (2003): "La fuente en el ámbito de las organizaciones políticas: los recursos del periodista especializado", en LOSADA VÁZQUEZ, Ángel y ESTEVE RAMÍREZ, Francisco (coords.): El periodismo de fuente. Salamanca, Universidad Pontificia de Salamanca, pp. 221-235.

BORRAT, Héctor (1989): El periódico: actor político. Barcelona, Editorial Gustavo Gili SA.

CASERO RIPOLLÉS, Andreu y LÓPEZ RABADÁN, Pablo (2013): "La gestión de las fuentes informativas como criterio de calidad profesional", en GÓMEZ MOMPART, Josep Lluís; GUTIÉRREZ LOZANO, Juan Francisco y PALAU SAMPIO, Dolors: La calidad periodística. Teorías, investigaciones y sugerencias profesionales. Barcelona, Castellón y Valencia; UAB, UPF, UJI y UV, pp. 73-89.

CYTRYNBLUM, Alicia (2009): Periodismo social: una nueva disciplina. Buenos Aires, La Crujía.

DÍAZ NOSTY, Bernardo (2011): Libro negro del periodismo en España. Madrid,APM.

GARCÍA GORDILLO, María del Mar; BEZUNARTEA VALENCIA, Ofa y RODRÍGUEZ CRUZ, Inés (2013): "El Valor Agregado Periodístico, herramienta para el periodismo de calidad", en GÓMEZ MOMPART, Josep Lluís; GUTIÉRREZ LOZANO, Juan Francisco y PALAU SAMPIO, Dolors: La calidad periodistica. Teorias, investigaciones y sugerencias profesionales. Barcelona, Castellón y Valencia; UAB, UPF, UJI y UV, pp. 39-52.

GARCÍA GUTIÉRREZ, Antonio (ed.) (1999): Introducción a la Documentación Informativa y Periodística. Sevilla, MAD.

HERRERO AGUADO, Carmen y GARCÍA GORDILLO, María del Mar (2003): "Periodismo de fuente: de la información política a la de sucesos", en en LOSADA VÁZQUEZ, Ángel y ESTEVE RAMÍREZ, Francisco (coords.): El periodismo de fuente. Salamanca, Universidad Pontificia de Salamanca, pp. 245-262.

LÓPEZ HERNÁNDEZ, María Ángeles (2000): "La documentación, herramienta básica del periodista y del comunicador". Ámbitos: Revista internacional de comunicación, vol. 5 (segundo semestre), pp. 129-142.

LÓPEZ HERNÁNDEZ, María Ángeles y DOMÍNGUEZ DELGADO, Rubén (2012): "El valor documental del periodista como autor". Estudios sobre el Mensaje Periodístico, vol. 18, $\mathrm{n}^{\circ} 2$ (julio-diciembre), pp. 791-803. Madrid, Servicio de Publicaciones de la Universidad Complutense.

MAYORAL SÁNCHEZ, Javier (2005): "Fuentes de información y credibilidad periodística". Estudios sobre el Mensaje Periodístico, vol. 11, pp. 93-102. Madrid, Servicio de Publicaciones de la Universidad Complutense.

PÉREZ CURIEL, Concepción (2005): Estudio de las Fuentes de Información en el Periodismo Especializado: Estrategias de selección y tratamiento de las fuentes en las secciones periodísticas de El Mundo y El País. (Tesis doctoral). Dirigida por Carmen Herrero Aguado. Sevilla, Universidad de Sevilla. 
Rubén Rivas de Roca García es Graduado en Periodismo por la Universidad de Sevilla. Estudiante del máster oficial de Estudios Europeos de esa universidad. Ha colaborado durante dos años en investigaciones sobre calidad periodística, tema del que versó su trabajo de fin de grado. 